\title{
Analysis of equity in utilization of health services in Afghanistan using a national household survey
}

\author{
Farhad Farewar ${ }^{1}$, Khwaja Mir Ahad Saeed ${ }^{1}$, Abo Ismael Foshanji ${ }^{1}$, Said Mohammad Karim Alawi ${ }^{1}$, \\ Mohammad Yonus Zawoli ${ }^{2}$, Omarzaman Sayedi ${ }^{2}$, Wu Zeng ${ }^{3}$ \\ ${ }^{1}$ Health Economics and Financing Directorate, Ministry of Public Health, Kabul, Afghanistan; ${ }^{2}$ Health Sector Resiliency (HSR) Project, Palladium, \\ Kabul, Afghanistan; ${ }^{3}$ Georgetown University, Washington, DC, USA \\ Contributions: (I) Conception and design: F Farewar, O Sayedi, W Zeng; (II) Administrative support: None; (III) Provision of study materials or \\ patients: None; (IV) Collection and assembly of data: KMA Saaed, AI Foshanji, SMK Alawi, MY Zawoli; (V) Data analysis and interpretation: F \\ Farewar, KMA Saeed, AI Foshanji, SMK Alawi, W Zeng; (VI) Manuscript writing: All authors; (VII) Final approval of manuscript: All authors. \\ Correspondence to: Farhad Farewar. Health Economics and Financing Directorate, Ministry of Public Health, Kabul, Afghanistan. \\ Email: hefd.farewar@gmail.com.
}

Background: Afghanistan has made significant progress in improving the health status of its population by improving access, coverage, and quality of health services since 2002. As a result, child and maternal mortality rates have considerably decreased. Despite this progress, however, concerns have been increasing over inequity in the utilization of health care.

Methods: Data from the Afghanistan Living Conditions Survey (ALCS 2016/17) were analyzed to examine inequities in using health care. Wealth was measured using consumption of both consumables and durable goods. Key health services studied were inpatient and outpatient care use in the public and private sectors. The use of inpatient and outpatient care was compared by wealth status, marriage status, age group, gender, and education level using $\mathrm{F}$ tests. Logistic and negative binomial regression models were used to examine factors associated with the utilization of outpatient and inpatient care, respectively. Concentration indexes (CIs), the composite measure of inequalities, were generated for both outpatient and inpatient services, and CIs were broken down by potential drivers of the inequalities.

Results: The study shows that households in the wealthiest quintile used more outpatient and inpatient health care compared to those in the poorest quintile. Overall utilization of inpatient and outpatient care was pro-rich, with a CI of 0.123 and 0.174 , respectively. There was greater inequality in utilization of health services provided by private health facilities, with a CI of 0.288 and 0.234 for outpatient and inpatient care, respectively. The use of health services in public facilities was more evenly distributed among the population, with CIs close to zero (0.014 and 0.093 for outpatient and inpatient services, respectively). The breakdown of CIs shows that location was one of key drivers of inequalities in utilization of care, which prevailed in both inpatient and outpatient health services.

Conclusions: There is significant inequality in the use of inpatient and outpatient care in Afghanistan. Although the utilization of health services in public facilities is more equal, the utilization of care in private facilities is pro-rich. As the private sector provides more than half of outpatient care services, it is critical to address this inequality. Improving physical access and quality of care in public facilities, and expanding programs that address potential financial barriers, could help reduce the inequity.

Keywords: Inequity; inequality; utilization of care; Afghanistan

Received: 07 May 2020. Accepted: 28 September 2020; Published: 25 December 2020.

doi: 10.21037/jhmhp-20-63

View this article at: http://dx.doi.org/10.21037/jhmhp-20-63 


\section{Introduction}

Since 2002, Afghanistan has made significant progress in improving the health status of its population by expanding access to and coverage of health services, in addition to enhancing the quality of health services. The population's access to health services within a two-hour travel distance has increased substantially, from nine percent in 2002 to nearly $87 \%$ in 2014 , and to over $90 \%$ in $2018(1,2)$. Accompanying the upward trend in health services coverage is the downward trend in infant, under-five, and maternal mortality rates, which exemplifies the improvement in health outcomes. Despite the overall improvement in the country's health status and health services, improving equity in health services utilization is of concern to the Government of Afghanistan, particularly with regard to services used by the poor and other vulnerable populations.

According to findings from the Afghanistan Health Survey 2018 (AHS), three-quarters of people who had a health complaint sought treatment outside their homes. In addition, the AHS suggest that access to treatment varies from $64.8 \%$ among those in the lowest wealth quintile to $80.5 \%$ in the high-income quintile. The AHS also estimated that utilization of private health sector services accounted for nearly two-thirds of the cases that sought care. Clinics funded or operated by the Ministry of Public Health $(\mathrm{MoPH})$ served $21.1 \%$ of cases, and MoPH hospitals served $9.4 \%$ of cases. MoPH clinics were more frequently used by rural residents $(25.9 \%)$ compared to urban $(9.9 \%)$ and by those in the lowest quintile (35.6\%) (2). These statistics suggest the existence of inequality in the use of health care in Afghanistan.

As equity is a critical element in evaluating the performance of a country's health system, many countries have conducted equity analyses to provide evidence for more informed decision making by identifying at-risk and vulnerable populations that are left behind in using health care services. For example, an equity study examining maternal and child health services $(\mathrm{MCH})$ in Thailand showed that socioeconomic factors, especially education, had effects on health outcomes (3). Mothers or caregivers with the highest level of education had a better result across all health outcome indicators compared to those without formal education (4).

A study in Malawi (5) found that the rich used selected health services more often than the poor. In some countries, although interventions to increase overall utilization of health care were implemented, the benefits varied significantly among populations, with the rich sometimes benefiting more from such interventions. A study of poor and non-poor pregnant women in western rural China reported that the use of $\mathrm{MCH}$ services was unequal (6). Since early 2000, health insurance coverage in China has expanded substantially. However, it was found that insurance benefited the rich more than the poor, and that resources were disproportionately used by the rich, exacerbating the inequality (7).

Afghanistan has been facing a triple-disease burden of communicable diseases, non-communicable diseases, and injuries. In addressing preventable $\mathrm{MCH}$ conditions, the Government of Afghanistan, with support from donors, has collaborated with development partners to pilot, implement, and monitor health programs, including those targeting the poorest populations. As a result, the country has systematically recorded core MCH health indicators through household surveys, such as the Multiple Indicator Cluster Survey, and the 2018 AHS. Indicators such as skilled birth attendance, antenatal care coverage, contraceptive prevalence rate, and child immunization are regularly tracked. These surveys contain information critical to understanding the inequality of health care use among different populations.

In this study, we used the Afghanistan Living Conditions Survey (ALCS 2016/17), which contains comprehensive information about the socioeconomic status of the population to estimate inequity in the use of inpatient and outpatient care in the public and private sectors. The survey produced information at the national and provincial levels, tracked seasonality of indicators, and is the only national survey that includes Afghanistan's nomadic Kuchi population.

We present the following article in accordance with the SURGE reporting checklist (available at http://dx.doi. org/10.21037/jhmhp-20-63).

\section{Methods}

Conceptually, inequality considers any difference in health utilization among population groups, while inequity includes only unjustified inequality. Thus, to understand inequity, a breakdown of inequality into justifiable and unjustifiable inequality is needed.

\section{Data source}

To conduct an inequality and inequity analysis of 
utilization of health services requires information on (I) wealth status, such as household assets, income, and expenditure; (II) utilization of health services, such as use of inpatient care, outpatient care, child care, or maternal care; and (III) factors that explain the inequality (e.g., age, gender, education, and location). In this study, we extracted data from the ALCS 2016/17, which was the most recent national survey of household living conditions in Afghanistan (8). The survey collected data not only on the socioeconomics and demographics of individuals (e.g., age, gender, education, employment), but also on household characteristics. It provided data on expenditures and assets, detailed information on utilization of health care, education attendance, and food security.

The survey used a two-stage sampling approach, consisting of 35 strata with 34 provinces and one stratum for the nomadic Kuchi population. In the first stage, for each stratum, enumeration areas (EAs) were sampled with probability proportional EA size. In the second stage, ten households were randomly selected as the Ultimate Sampling Unit. In total, about 21,000 households and more than 150,000 persons were included in the survey. The detailed sampling process is described in the ALCS (8).

\section{Measurement}

As mentioned above, key data for conducting the equity analysis included wealth status, use of health services, and potential explanatory variables for inequality. Below, we provide more detailed information on how these three types of variables were measured.

\section{Measurement of wealth status}

Wealth status was measured using the annual total consumption within a household. In order to identify a precise measure of wealth status, the survey asked about monthly consumption of 21 consumables (such as food, cigarettes, tobacco, soap, shampoo, charges for mobile phone, and transportation), and yearly consumption of 19 durable goods (such as shoes, clothing, education fees, and textbooks). The monthly consumption of consumables was multiplied by 12 to generate yearly estimates. The study estimated the total annual consumption by summing the annual consumption of consumables and durable goods. Adjusting total annual consumption for household size, by generating annual consumption per capita, the study provided an estimate of the wealth status of the household. The households were then divided into five quintiles based on the consumption per capita.

\section{Measurement of utilization of health care services}

The survey asked if respondents had been admitted to a hospital for inpatient care in the last 12 months, and if they sought care for outpatient care in the month prior to when the survey was administered. For inpatient care, respondents were asked how many admissions occurred during the last year. Therefore, the outcome variable took values such as 0 , $1,2,3,4$ or more. The survey did not ask for the number of visits for outpatient care, and so we only know if individuals sought care in the last month. Additionally, the survey provided information on where services were obtained for the last admission/visit. This allowed us to conduct an analysis of service utilization by health facility type at public facilities (e.g., national hospital, regional hospitals, provincial hospitals, district hospitals, poly clinics, and other public clinical units) or private facilities (e.g., private hospitals, private clinics, and other private clinical units).

\section{Measurement of potential explanatory variables}

The study used five variables as potential explanatory variables: age, gender, marriage status, education status, and location of households. The survey asked the age of individual members of the household and age is noted as a continuous variable. For our analysis, we recoded age as an ordered variable, with age groups of 0-10 years old, 11-20 years old, 21-30 years old, 31-40 years old, 41-50 years old, 51-60 years old, and $60+$ years old. The study categorized gender as male (coded as 1 ) and female (coded as 0 ). And for marriage status, the study created five categories: married, widowed, divorced, or separated, engaged, and never married.

For our analysis, we re-categorized marriage status as married (coded as 1 , consisting of the first three categories) and not married (coded as 0 , consisting of the latter two categories). We also reduced the number of categories for location of households from three (urban, rural, and Kuchi) to two (urban and rural, where rural combines rural and Kuchi). Given that the majority of the Afghan population does not receive an education, we also recoded the education level into two levels: Those who did not attend school were classified as a "no education" group (education $=0$ ) and those who attended school were classified as a "some education" group (education $=1$ ).

\section{Analysis}

A descriptive analysis of the population was conducted. Use 
Table 1 Demographic characteristics of surveyed sample

\begin{tabular}{lc}
\hline Characteristics & Mean \pm standard error or percentage \\
\hline Household size & $7.70 \pm 0.03$ \\
Age (years) & $20.50 \pm 0.05$ \\
Age groups (years) & \\
$0-10$ & $33.81 \%$ \\
$11-20$ & $24.77 \%$ \\
$21-30$ & $16.11 \%$ \\
$31-40$ & $9.55 \%$ \\
$41-50$ & $6.94 \%$ \\
$51-60$ & $4.45 \%$ \\
$60+$ & $4.37 \%$ \\
Marriage & \\
Not married & $60.82 \%$ \\
Married & $39.18 \%$ \\
Residency & \\
Rural & $76.24 \%$ \\
Urban & $23.76 \%$ \\
No education & \\
\hline Some education & $69.78 \%$ \\
\hline
\end{tabular}

of inpatient and outpatient care was compared by wealth status, marriage status, age group, gender, and education using $\mathrm{F}$ tests or $t$-tests. We used logistic and negative binomial regression models to examine factors associated with the utilization of outpatient and inpatient care, respectively.

We conducted the key analysis of inequality by generating concentration indexes (CIs) and concentration curves. The CI is defined in terms of the concentration curve and takes a value of between zero and one. The concentration curve plots the cumulative percentage of the health variable on the $Y$ axis against the cumulative percentage of the population, ranked by socioeconomic status beginning at the poorest and ending with the richest on the $\mathrm{X}$ axis. If everyone has exactly the same value of the health variables, the concentration curve will be a 45-degree line (line of equality). The further the curve is from the line of equality, the more concentrated the degree of health inequality (9). The CI provides a measure of the magnitude of inequality. If the index takes a negative value when the curve lies above the line of equality, this indicates a disproportionate concentration of the health variable among the poor. The CI takes a positive value when it lies below the line of equality.

We conducted all analyses using Stata. To estimate the $\mathrm{CI}$ and generate the concentration curves, we followed the approach and used the Stata command proposed by O'Donnell et al. (9). The study was conducted in accordance with the Declaration of Helsinki (as revised in 2013). Since we were using the secondary data for which an IRB approval and informed consent was already secured, we assume no further consent and IRB approval was required for this.

\section{Results}

The ALCS survey contained 21,000 households and more than 150,000 persons. The average age in the sampled population was 20.50 years old (Table 1 ). Children $0-10$ years old accounted for $33.81 \%$ of the sampled population, the largest share in the sample; those 11-20 years old accounted for $24.77 \%$, the second largest in the sample. The survey also shows that the majority of the population lived in rural areas, accounting for $76.24 \%$ of the sampled population; $69.78 \%$ of the sampled population had no education.

Table 2 shows the utilization of outpatient and inpatient care by individuals based on their affiliation to one of the wealth quantiles, age group, gender, marital status, location, and education. The results show that with the increase of wealth status, the use of outpatient care and private outpatient care consistently increased. Just $3.9 \%$ of the population in the lowest quintile used outpatient care in the month prior to the survey, as compared to $13.0 \%$ of those in the highest wealth quintile. However, using public outpatient care did not show a consistent pattern. The use of public outpatient care peaked among those in the third quintile.

Overall, the utilization of care among different age groups was in a "U" shape, with relatively higher utilization among those 1-10 years old and lower utilization among those 11-20 years old, and a continuous increase of utilization as people aged. The percentage of the population using overall outpatient care in the month before the survey ranged from 0.046 to 0.171 ; the percentage using inpatient care in the year before the survey ranged from 0.0022 to 0.141 . There were differences of use of overall, public, and private outpatient and inpatient care among different age groups $(\mathrm{P}<0.05)$. Females used more outpatient and 
Table 2 Utilization of outpatient and inpatient care by household characteristics

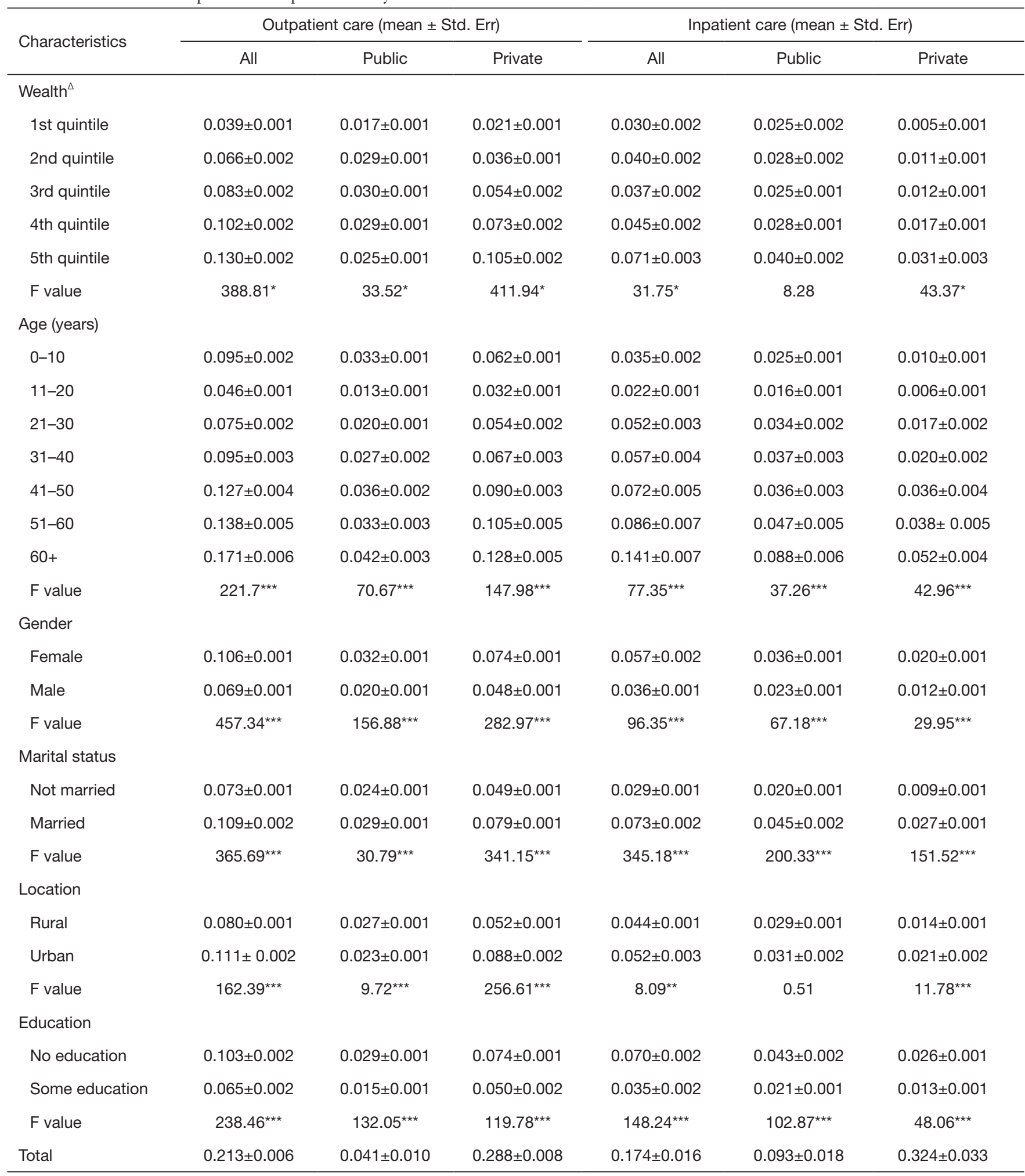

${ }^{\star}, \mathrm{P}<0.05 ;{ }^{* \star}, \mathrm{P}<0.01 ;{ }^{* \star \star}, \mathrm{P}<0.001 .{ }^{\Delta}$, 1st quintile are the poorest households, 5th quintile are the richest households; Std. Err., standard error. 
Table 3 Logistic regression model for outpatient care (odds ratio)

\begin{tabular}{lccc}
\hline Explanatory variables & Overall & Public & Private \\
\hline Wealth quintile & $1.356^{\star \star \star}$ & $1.073^{\star \star \star}$ & $1.475^{\star \star \star}$ \\
Age & $1.269^{\star \star \star}$ & $1.208^{\star \star \star}$ & $1.268^{\star \star \star}$ \\
Male & $0.388^{\star \star *}$ & $0.350^{\star \star *}$ & $0.428^{\star \star \star}$ \\
Marriage & $1.435^{\star \star \star}$ & $1.503^{\star \star \star}$ & $1.398^{\star \star \star}$ \\
Urban & $1.168^{\star \star \star}$ & $0.863^{\star}$ & $1.280^{\star \star \star}$ \\
Education & $0.882^{\star \star \star}$ & 0.947 & $0.862^{\star \star}$ \\
Constant & $0.015^{\star \star \star}$ & $0.011^{\star \star \star}$ & $0.007^{\star \star \star}$ \\
\hline
\end{tabular}

${ }^{*}, \mathrm{P}<0.05 ;{ }^{* *}, \mathrm{P}<0.01 ;{ }^{* \star *}, \mathrm{P}<0.001$.

inpatient care compared to males. For example, on average, $10.6 \%$ of females sought outpatient care in the month before the survey was conducted, compared to $6.9 \%$ of males. The difference was statistically significant $(\mathrm{P}<0.001)$.

Health care utilization among married people was higher compared to not-married people, both for outpatient and inpatient care, no matter whether it was public or private outpatient or inpatient care. On average, $10.9 \%$ of married people, compared to $7.3 \%$ of not-married people, sought outpatient care during the month prior to the survey. The difference was statistically significant $(\mathrm{P}<0.01)$. Similarly, $7.3 \%$ of married people, in comparison to $2.9 \%$ of notmarried people, were admitted to the hospital for inpatient care one year prior to the survey. The difference was statistically significant $(\mathrm{P}<0.001)$. Overall, people who lived in urban areas used more inpatient and outpatient care than those who resided in rural areas.

Taking overall outpatient care as an example, about $3.1 \%$ more people sought outpatient care in urban areas than in rural areas $(11.1 \%$ vs. $8.0 \%)$. The difference was statistically significant $(\mathrm{P}<0.001)$. However, in the case of public outpatient care, use of care was lower in urban areas compared to rural areas (2.3\% vs. $2.7 \%)$. In private facilities, whether for outpatient or inpatient care, people in urban areas used more care than those in the rural areas. Health care utilization among people with no education was higher than among people with some education (Table 2, $10.3 \%$ vs. $6.5 \%$ for overall outpatient, and $7.0 \%$ vs. $3.5 \%$ for overall inpatient care). These differences were statistically significant $(\mathrm{P}<0.001)$.

The logistic regression model examining factors associated with outpatient care utilization shows that wealth quintile, age, education, location, and marital status were all associated with the utilization of outpatient health care
(Table 3). Wealth, age, marital status, and location were positively associated with the use of outpatient care (overall private and public outpatient care), while being male and with some education was negatively associated with the use of outpatient care.

If the wealth were increased by one quintile, the odds of using overall outpatient care would increase by $35.6 \%$; increasing category in one age ladder would increase the odds by $26.9 \%$; being male reduced odds by $61.2 \%$; being married was associated with $43.5 \%$ higher odds; living in urban areas was associated with $16.8 \%$ higher odds; and have some education was associated with $11.8 \%$ reduced odds. All these factors were statistically significant $(\mathrm{P}<0.001)$.

For the use of outpatient care in public facilities, the odds of using the care would increase by $7.3 \%$ if wealth increased by one quintile. Raising one category in the age ladder increased the odds by $20.8 \%$. Being married increased the odd by $53.6 \%$. Being male and residing in an urban area was negatively associated with the utilization of outpatient care in public facilities. The odds of males using public outpatient care was $35.0 \%$ of females using care. Those residing in urban areas had $13.7 \%$ lower odds of using public outpatient care than those residing in rural areas. Education was not associated with the use of public outpatient care.

For outpatient care in private health facilities, we found that wealth status, age, marital status, and location were positively associated with the use. If the wealth quintile were to increase by one unit, the odds of utilization of private outpatient care would increase by $47.5 \%$. Increasing age by one category in the age ladder up, the odds of using private outpatient care would increase by $26.8 \%$. Being married was associated to increased odds by $39.8 \%$. Residence in urban areas increased the odds by $28.0 \%$. Being male and having some education reduced the odds of use of private outpatient care by $57.2 \%$ and $13.8 \%$, respectively.

The negative binomial regression model for examining factors associated with inpatient care utilization shows that wealth, age, gender, and marital status were associated with the use of inpatient care, while location and education were not (Table 4).

If the wealth quintile and age ladder increased by one unit, the use of overall inpatient care would increase by $18.3 \%$ and $26.3 \%$, respectively $(\mathrm{P}<0.001)$. People who were married used $40.1 \%$ more inpatient care than those who were not married $(\mathrm{P}<0.001)$. Males used $75.6 \%$ less inpatient care than females did $(\mathrm{P}<0.001)$.

For determinants of inpatient care in public facilities, 
Table 4 Negative binomial regression model for inpatient care

\begin{tabular}{|c|c|c|c|}
\hline Explanatory variables & Overall & Public & Private \\
\hline Wealth quintile & $0.183^{\star \star \star}$ & $0.107^{\star \star \star}$ & $0.344^{\star \star \star}$ \\
\hline Age & $0.262^{\star \star *}$ & $0.227^{\star \star *}$ & $0.327^{\star \star \star}$ \\
\hline Male & $-0.756^{\star \star \star}$ & $-0.810^{\star \star \star}$ & $-0.633^{\star \star \star}$ \\
\hline Marriage & $0.401^{\star * *}$ & $0.434^{\star \star *}$ & $0.346^{\star \star}$ \\
\hline Urban & -0.044 & -0.084 & 0.014 \\
\hline Education & -0.041 & -0.047 & -0.046 \\
\hline Constant & $-4.54^{\star \star \star}$ & $-4.574^{\star \star \star}$ & $-6.484^{\star \star \star}$ \\
\hline
\end{tabular}

${ }^{*}, \mathrm{P}<0.05 ;{ }^{* \star}, \mathrm{P}<0.01 ;{ }^{* \star}, \mathrm{P}<0.001$.

Table 5 Concentration index for outpatient and inpatient care $($ mean \pm Std. Err $)$

\begin{tabular}{lcc}
\hline Sector & Outpatient & Inpatient \\
\hline Overall & $0.213 \pm 0.006$ & $0.174 \pm 0.016$ \\
Public & $0.041 \pm 0.010$ & $0.093 \pm 0.018$ \\
Private & $0.288 \pm 0.008$ & $0.324 \pm 0.033$ \\
\hline
\end{tabular}

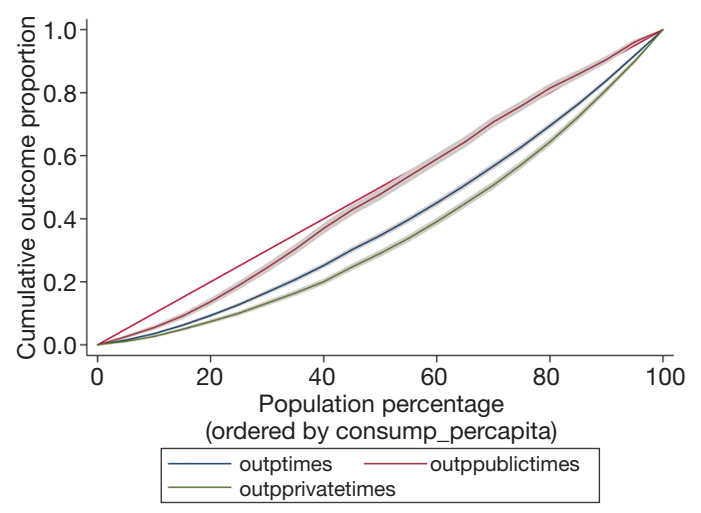

Figure 1 Concentration curve for outpatient care.

the same pattern occurred as for overall inpatient care. Increasing the wealth status by one unit was associated with a $10.7 \%$ increase in the utilization of public inpatient care $(\mathrm{P}<0.001)$. Those married used $43.4 \%$ more public inpatient care than those not married $(\mathrm{P}<0.001)$. Gender was also associated with health care utilization. Being male significantly reduced utilization of inpatient care by $81 \%$ $(\mathrm{P}<0.001)$.

Being wealthy, older, and married were associated with increased use of inpatient care from private facilities. Rising one step in the wealth ladder increased utilization of private

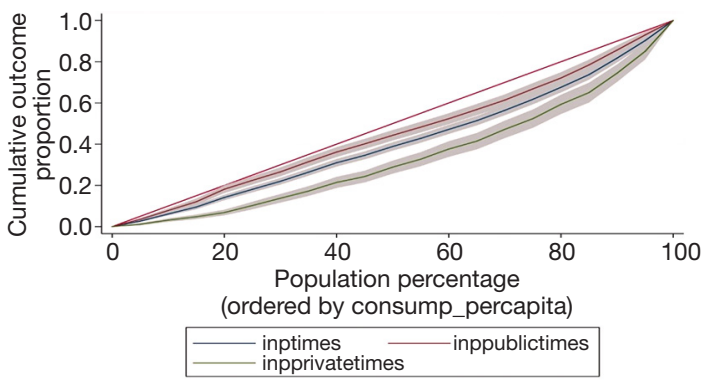

Figure 2 Concentration curve for inpatient care.

inpatient care by $34.4 \%(\mathrm{P}<0.001)$; each category up the age ladder increased the use of private inpatient care by $32.7 \%$ $(\mathrm{P}<0.001)$. Those married used inpatient care from private health care facilities $34.6 \%$ more than their not-married comparators $(\mathrm{P}<0.001)$. Gender was also associated with use of private inpatient care. Being male decreased inpatient health care utilization from a private health care facility. Males used $63.3 \%$ less private inpatient health care than females $(\mathrm{P}<0.001)$.

The estimated CIs (Table 5) show that the overall utilization of outpatient care and inpatient care tended to be pro-rich, with values of 0.213 and 0.174 for outpatient care and inpatient admissions, respectively. When separating care by public and private settings, we found that the CIs were greater for the utilization of private facilities, with 0.288 and 0.324 for outpatient visits and inpatient admission, respectively. This shows that there was a greater inequality in seeking care in private facilities and that it was pro-rich. The CIs for the use of health care in public facilities were close to zero (0.041 and 0.093 for outpatient and inpatient services, respectively), indicating both poor and rich used public health facilities almost equally.

Figures 1,2 show the concentration curves of outpatient and inpatient visits, respectively. If the curve falls above the line of equality, it indicates a tendency of pro-poor, whereas if curves fall below the line of equality, it favors the wealthy. As shown in Figures 1,2, concentration curves for outpatient and inpatient care fell below the line of equality, indicating that the use of care was in favor of the wealthy. Concentration curves for health services in public facilities tended to fall closer to the line of equality as compared to those for services obtained at private facilities.

Figures 3,4 show the decomposition of inequality for outpatient and inpatient care, respectively, by potential determinant (e.g., age, gender, marriage, urban, and education). It is clear that a significant portion of inequality 


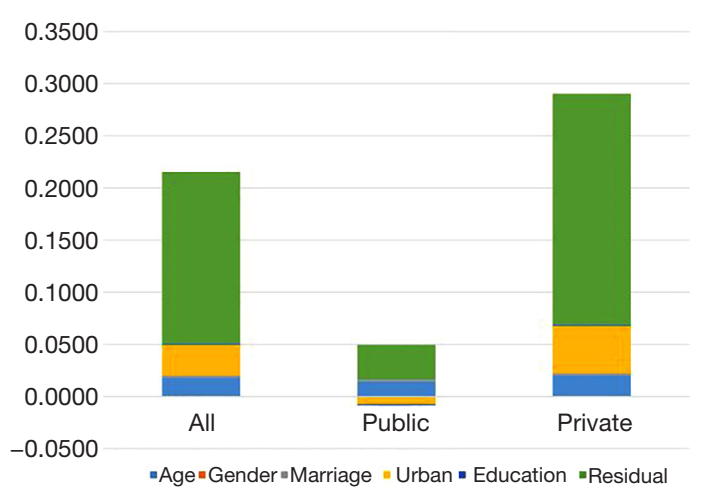

Figure 3 Decomposition of concentration index for outpatient visits.

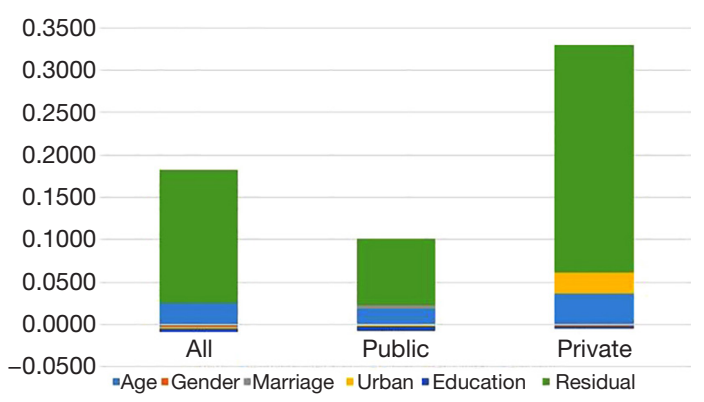

Figure 4 Decomposition of concentration index for inpatient admission.

could not be explained by the above factors as the residual presented the largest portion of the CIs.

Among the known factors, location was the major factor contributing to the inequality for outpatient care. It contributed to $14 \%$ and $16 \%$ of the CI for overall and private outpatient care, respectively. Age was another factor contributing to the inequality, accounting for $8.3 \%$ and $6.7 \%$ of inequality for overall and private outpatient care, respectively.

In terms of the contributors for inpatient care, age was the key factor, accounting for $14.5 \%, 20.4 \%$, and $11.5 \%$ of inequality for overall, public, and private inpatient care, respectively. Location was also a factor explaining the inequality for overall inpatient care and private inpatient care, contributing $4.3 \%$ and $7.5 \%$ of the inequality, respectively.

\section{Discussion}

This study shows that there is substantial inequality in the use of inpatient and outpatient health care in Afghanistan. Overall, the inequality is pro-rich, suggesting that the rich use more health care services than the poor. Our findings also show that wealth status, age, marital status, location, and education are associated with the use of outpatient and inpatient care. Further decomposition of inequality suggests that the major inequality lies in the use of inpatient and outpatient care from private providers; the use of health services from public health facilities is more evenly distributed among the population with different socioeconomic status.

The existence of inequality in use of health services is consistent with findings from earlier studies conducted in Afghanistan (10,11). On average, utilization remains low among those in the lower income quintile, compared to those in the higher-income quintile. Despite this, public health facilities are more equally used regardless of wealth status, which suggests that significant investment in public health facilities helps reduce the inequality of health service utilization. In fact, a prior study in Afghanistan showed that the use of public health services was pro-poor (11) and facilitated the timely use of care and treatment.

The core of Afghanistan's health service delivery system comprises the Basic Package of Health Services (BPHS), which focuses on primary care, and the Essential Package of Hospital Services (EPHS), which covers secondary care. Both packages are provided free of charge through nongovernmental organizations (NGOs) or government facilities. Service utilization improved substantially upon implementation of the two packages. Given the high poverty rate among Afghans, with the majority living with limited resources, it is expected that the government and NGOs will continue to play a critical role in meeting the population's health needs, particularly of those in rural areas. Since majority of out of pocket payment made in 2017 is on medicine and diagnostics, maintaining sufficient stock of medicine in public health facilities is paramount in improving equity.

Private health facilities comprise various categories from doctors' offices to complex hospitals. Consistent to the prior studies in Afghanistan $(12,13)$, we found that more than half of outpatient care is provided by private health facilities. While this means there is a vibrant private market for health service delivery (more flexible hours of operation and relatively better treatment of personnel may be two factors for this), it may also signal that the public health service delivery system is not functioning as expected specially when all of the private health facilities are financed out of 
pocket. Despite the impressive improvement in expanding access to health care under BPHS and EPHS, there remain many challenges, of which the poor quality of care is a major concern $(14,15)$. Developing quality improvement processes and interventions targeting specific quality concerns would help address the inequality concern in using the care.

As expected, wealth is strongly associated with the use of health care, both public and private, which suggests affordability is a prevalent concern of access to health services, even for free care provided in public health facilities. However, ability to pay decides access to services from the private sector, anecdotes suggest that those not financially privileged incur catastrophic health spending when accessing services. Despite free consultations in public facilities, when seeking care, the poor often incur out-ofpocket expenses to cover such costs as transportation, meals, medicine, diagnostic tests, and accommodations.

For instance, it is not unusual for patients to have to purchase drugs from private pharmacies, due to the stock out of medicine in public facilities, and to pay for laboratory tests and imaging services conducted in the private sector due to unavailability of such services in public facilities. In fact, out-of-pocket health expenditures account for more than $75.5 \%$ of the country's total health expenditures (14), which puts a great financial burden on households and exacerbates inequity. Approximately $14 \%$ of the population is dragged into poverty for having to pay to access health care at the point of services (14).

The decomposition of inequality and the regression models show that location is an important factor explaining the disparity in utilization of care. For instance, living in urban areas is positively associated with care in private health facilities. There are several reasons for this finding. First, there is greater availability of private-sector health services in urban areas. The number of private health facilities increased substantially due to the government's support, as it considers them a vital part of the national health system (16). Taking licensed private hospitals as an example, the number increased from 14 in 2003 to 319 in 2014 (12), most of them in the urban areas. Second, urban health facilities are more accessible; physical access to care in remote areas has long been an issue for those seeking care. The Government of Afghanistan has taken some initiatives to improve access, such as establishing mobile clinics and providing referral transportation support.

Contrary to our expectation, those with no education used more healthcare as compared to those with some education. This might be due to the fact that majority in the sample has no education. Also, important to note that there might be little difference in level of education between these two categories. Other important factor in healthcare utilization by those with no education can be the fact that those with no education be relatively poor as well. Therefore, chances are they become ill more often and use services at a higher frequency.

Our finding of a negative association of residing in urban areas with health care utilization of public health facilities is interesting. It is probably due to the BPHS targeting rural areas, over urban areas. Another possibility of the negative association is the growing network of private health facilities in urban areas. In areas where there is an issue of physical access to health care, particularly public health services, using private health facilities to fill the service gap would be critical in expanding health services among the population. Establishing a prepayment arrangement that allows for purchasing services from the private sector could alleviate financial catastrophe caused by people incurring out-ofpocket expenses when using private sector health services.

Public and private outpatient and inpatient care utilization follows a "U" shape pattern. That is the utilization is higher among the age group of $1-10$, which might be due to the still higher prevalence of infectious disease among children, followed with lower utilization among the age group of 11-20, and increase of utilization as people get older. The last is consistent with the pattern of healthcare utilization elsewhere in the world as we grow old, we are more likely to develop chronic diseases as a result of which our healthcare need increases. Based on our analysis moving one category up in the age categories increases the use of health care services from both public and private health facilities. This is understandable: As people age, the need and demand for health services increases. However, the current BPHS and EPHS packages supported by donors offer very limited services for older people, which might put them at risk of incurring catastrophic health expenses. Therefore, any revisions to the scope of the packages should consider including services for adults, especially interventions for common non-communicable diseases that occur more often in the elderly.

\section{Conclusions}

Finally, inequality of using inpatient and outpatient care remains a concern in Afghanistan. The BPHS and EPHS packages that target the poor and remote populations have reduced the magnitude of the inequality. Addressing quality 
of care concerns, improving physical access to care, and expanding the availability of care by progressively increasing the prepaid share of total health spending, could potentially address the inequality in the utilization of health services in Afghanistan. Also important is to make all efforts to address demand side factors such as socio-cultural barriers to obtaining services when making expansion decisions.

\section{Acknowledgments}

Analyzing equity in health service utilization is critical to identify risk or vulnerable population who are left behind in using health services. This study, "An Equity Analysis of Health Service Utilization in Afghanistan", was made possible by the joint effort of dedication from the Ministry of Public Health (MoPH) and technical partners. Seizing this opportunity, we would like to appreciate the effort that was taken by Health Economics and Financing Directorate (HEFD), led by Dr. Farhad Farewar, to carry out the assignment. We would also appreciate Dr. Abo Ismael Foshanji, Dr. Sayed Karim Alawi and Khwaja Mir Ahad for their participation and effort in collecting, and analyzing data and producing the report. Finally, we would like to highly value the support of USAID-funded Health Sector Resilience (HSR) project, principally Dr. Wu Zeng and Mr. Mohammad Yonus Zawoli, for the vital role they played in technically assisting HEFD with the data analysis and finalizing this report.

The authors acknowledge and appreciate the work of all officers in HEFD who provided them with backstop support providing them with data required as and when needed.

Funding: The study has been supported by the USAID financed HSR project.

\section{Footnote}

Provenance and Peer Review: This article was commissioned by the editorial office, Fournal of Hospital Management and Health Policy for the series "Incentives and health system efficiency in low- and middle-income countries". The article has undergone external peer review.

Reporting Checklist: The authors have completed the SURGE reporting checklist. Available at http://dx.doi. org/10.21037/jhmhp-20-63

Peer Review File: Available at http://dx.doi.org/10.21037/ jhmhp-20-63

Conflicts of Interest: All authors have completed the ICMJE uniform disclosure form (available at http://dx.doi. org/10.21037/jhmhp-20-63). The series "Incentives and health system efficiency in low- and middle-income countries" was commissioned by the editorial office without any funding or sponsorship. Wu Zeng served as the unpaid Guest Editor of the series and serves as an unpaid editorial board member of Fournal of Hospital Management and Health Policy from August 2019 to July 2021. The authors have no other conflicts of interest to declare.

Ethical Statement: The authors are accountable for all aspects of the work in ensuring that questions related to the accuracy or integrity of any part of the work are appropriately investigated and resolved. The study was conducted in accordance with the Declaration of Helsinki (as revised in 2013). Since we were using the secondary data for which an IRB approval and informed consent was already secured, we assume no further consent and IRB approval was required for this.

Open Access Statement: This is an Open Access article distributed in accordance with the Creative Commons Attribution-NonCommercial-NoDerivs 4.0 International License (CC BY-NC-ND 4.0), which permits the noncommercial replication and distribution of the article with the strict proviso that no changes or edits are made and the original work is properly cited (including links to both the formal publication through the relevant DOI and the license). See: https://creativecommons.org/licenses/by-nc-nd/4.0/.

\section{References}

1. Afghanistan Ministry of Public Health. National Health Strategy 2016-2020. Kabul, Afghanistan: MoPH. 2016. Available online: https://afghanhealth1stopshop.org/ download/national-health-strategy-2016-2020/

2. Afghanistan Ministry of Public Health, National Statistics and Information Authority of Afghanistan A, Institute KRT. Afghanistan Health Survey 2018. Kabul, 2019. Available online: https://www.kit.nl/wp-content/uploads/2019/07/ AHS-2018-report-FINAL-15-4-2019.pdf

3. Limwattananon S, Tangcharoensathien V, Prakongsai P. Equity in maternal and child health in Thailand. Bull World Health Organ 2010;88:420-7.

4. Zhu D, Guo N, Wang J, Nicholas S, et al. Socioeconomic 
inequalities of outpatient and inpatient service utilization in China: Personal and regional perspectives. Int J Equity Health 2017;16:210.

5. Zere E, Moeti M, Kirigia J, et al. Equity in health and healthcare in Malawi: Analysis of trends. BMC Public Health 2007;7:78.

6. Shen Y, Yan H, Reija K, et al. Equity in use of maternal health services in western rural China: A survey from Shaanxi province. BMC Health Serv Res 2014;14:155.

7. Wang H, Zhang L, Yip W, et al. Adverse selection in a voluntary rural mutual health care health insurance scheme in China. Soc Sci Med 2006;63:1236-45.

8. Central Statistics Organization. Afghanistan Living Conditions Survey 2016-17. 2018. Kabul, CSO. Available online https://www.nsia.gov.af:8080/wp-content/ uploads/2019/04/ALCS-2016-17-Analysis-report-.pdf

9. Donnell O, Van Doorslaer E, Wagstaff A, et al. Analyzing health equity using household survey data: a guide to techniques and their implementation. Washington, DC: World Bank, 2008.

10. Trani JF, Barbou-des-Courieres C. Measuring equity in disability and healthcare utilization in Afghanistan. Med

doi: 10.21037/jhmhp-20-63

Cite this article as: Farewar F, Saeed KMA, Foshanji AI, Alawi SMK, Zawoli MY, Sayedi O, Zeng W. Analysis of equity in utilization of health services in Afghanistan using a national household survey. J Hosp Manag Health Policy 2020;4:34.
Confl Surviv 2012;28:219-46.

11. Kim C, Saeed KMA, Salehi AS, et al. An equity analysis of utilization of health services in Afghanistan using a national household survey. BMC Public Health 2016;16:1226.

12. Cross HE, Sayedi O, Irani L, et al. Government stewardship of the for-profit private health sector in Afghanistan. Health Policy Plan 2017;32:338-48.

13. Zeng W, Kim C, Archer L, et al. Assessing the feasibility of introducing health insurance in Afghanistan: a qualitative stakeholder analysis. BMC Health Serv Res 2017;17:157.

14. Afghanistan Ministry of Public Health. Afghanistan National Health Accounts 2017 (2019). Available online https://moph.gov.af/sites/default/files/2019-09/ Afghanistan \%20National\%20Health\%20Accounts\%20 2017_Final\%20(Annexes)\%2024-8-2019\%20-min.pdf

15. Afghanistan Ministry of Public Health. National Health Policy 2015-2020 (2012). Available online http://www. acbar.org/upload/1493096331346.pdf

16. Newbrander W, Ickx P, Feroz F, et al. Afghanistan's basic package of health services: Its development and effects on rebuilding the health system. Glob Public Health 2014;9 Suppl 1:S6-28. 